\title{
The effect of flame straightening on the microstructure and mechanical properties of different strength steels
}

\author{
László Gyura ${ }^{1} \cdot$ Marcell Gáspár ${ }^{2}$ (D) - András Balogh ${ }^{2}$ \\ Received: 14 September 2020 / Accepted: 18 December 2020 / Published online: 13 January 2021 \\ (C) The Author(s) 2021
}

\begin{abstract}
In many cases, flame straightening is unavoidable after welding for the reduction of deformation. Due to the not very concentrated heat source, the process can cause significant changes in the microstructure, especially in high strength and wear-resistant steels. Due to their different physical properties, the effects vary depending on the flammable gases (acetylene, propane). The situation is complicated by the fact that the manual technology carries a risk of overheating, which can have detrimental effects on the mechanical properties. During our experiments, three steels are investigated (S355J2 + N, XAR400, S960QL). The thermal cycles for the physical simulations were determined by thermocouple measurement during real experimental conditions. Three peak temperatures $\left(1000{ }^{\circ} \mathrm{C}, 800^{\circ} \mathrm{C}\right.$ and $675^{\circ} \mathrm{C}$ ) and two types of industrial cooling conditions (air and water cooling) were studied. The samples were examined by optical microscopy tests, hardness testing and Charpy V-notch impact tests. During straightening the XAR400 showed high sensitivity to softening even in the lower temperature range, while hardening occurred in the S960QL steel at a higher peak temperature values during water cooling. The inter- and supercritical temperature should be avoided in all steels; however, the subcritical temperature can be beneficial to the toughness properties of the S960QL and XAR400.
\end{abstract}

Keywords Flame straightening $\cdot$ Thermal cycles $\cdot$ High-strength steels $\cdot$ Gleeble simulation

\section{Introduction}

Flame straightening is based on the physical principle that metals expand when heated and shrink when cooled. This well-known technology is flame heating of metal constructions, with sharply outlined heating regions, up to flame straightening temperature and a simultaneous restriction of the expansion.

Recommended for publication by Commission IX - Behaviour of Metals Subjected to Welding

Marcell Gáspár

gasparm@uni-miskolc.hu

László Gyura

laszlo.gyura@linde.com

András Balogh

baloghandrasdr@t-online.hu

1 Linde Gas Hungary Ltd, Répcelak 9653, Hungary

2 Institute of Materials Science \& Technology, University of Miskolc, Miskolc 3515, Hungary
Although flame straightening is a technology that has been used frequently in the production of metal structures for a long time, we do not know much about the changes in the material structure due to heating, and this is especially true for high-strength steel structures. Without accurate knowledge, it is not easy to make a preliminary estimate of the expected impact of the heat source performance, heating time, temperature, extent, etc. The wellproven and developed cooling time concept according to EN 1011-2, which can be used to give a good estimate of the expected mechanical properties of the joint based on the calculation of the cooling time from arc energy (heat input), cannot be applied to flame straightening technologies. The situation is aggravated by the fact that in many cases, the technology is a manual intervention, in which heat input data are not easy to measure. Flame straightening typically initiates a significant process of austenitization and grain coarsening in the steel at high temperatures (minimum temperatures between $A_{1}$ and $A_{3}$, but occasionally above $A_{3}$ ) and for a relatively long time, which can cause significant changes in the microstructure under uncontrolled cooling conditions. 
Table 1 Recommendation for maximum values of the flame straightening temperature

\begin{tabular}{llll}
\hline Delivery condition & $\begin{array}{l}\text { Short superficial } \\
\text { heating }\end{array}$ & $\begin{array}{l}\text { Short full section } \\
\text { heating }\end{array}$ & $\begin{array}{l}\text { Full section heating with longer } \\
\text { holding time }\end{array}$ \\
\hline Normalized & $\leq 900{ }^{\circ} \mathrm{C}$ & $\leq 700{ }^{\circ} \mathrm{C}$ & $\leq 650{ }^{\circ} \mathrm{C}$ \\
Thermomechanical rolled up & $\leq 900{ }^{\circ} \mathrm{C}$ & $\leq 700{ }^{\circ} \mathrm{C}$ & $\leq 650{ }^{\circ} \mathrm{C}$ \\
$\quad$ to S460 & $\leq 900{ }^{\circ} \mathrm{C}$ & $\leq 600{ }^{\circ} \mathrm{C}$ & $\leq 550{ }^{\circ} \mathrm{C}$ \\
$\begin{array}{l}\text { Thermomechanical rolled } \\
\text { S500 to S700 }\end{array}$ & $\leq$ Tempering temperature applied to the original product $-20{ }^{\circ} \mathrm{C}$ \\
Quenched and tempered & &
\end{tabular}

The actual size of the heat-affected area and the heat cycle at a given point in the piece are influenced by several factors. Both the heating conditions (heating time and rate) and the cooling conditions (cooling time and rate) can be determinants of the developed material properties.

Based on the degree of heating, flame equalization can be divided into two cases. One commonly used technology is to partially heat the surface layer (typically up to $30-35 \%$ of the total cross-section) relative to the overall cross-section of the structure. The rate of heat input in this case is small relative to the material thickness of the workpiece, and the cooling rate is typically high. In the other case, when the entire cross-section of the workpiece is heated locally, a relatively high heat input and low cooling rate can be expected [1]. Since the steel is heated up in a relatively large area and depth, the influence of flame straightening on the material properties cannot be considered as any less significant than the welding.

Many studies have been conducted about the effect of $t_{8 / 5}$ cooling time on heat-affected zone characteristics. However, in most cases, a relatively short, 5-30 s cooling time interval is investigated in accordance with the typical range of the most common arc welding technologies [2-5]. In high strength steels, generally a narrow $(6-10 \mathrm{~s}) \mathrm{t}_{8 / 5}$ cooling time range is recommended, especially in the higher strength grades [6]. During flame straightening, the cooling time can be much longer (occasionally above $100 \mathrm{~s}$ ); therefore, it is worth gaining knowledge about the material's behaviour and microstructure and mechanical properties, in these cooling circumstances.

Although there are relatively few papers about the effect of flame straightening on structural steels, some useful information can be found in the literature. The consequences of the flame straightening on the microstructure, mechanical or fracture behaviour strongly depend on the nature of the material; therefore, general recommendations cannot be established. In one study [7], different grades of structural steels were investigated in flame straightening. Neither the hardness of S235JR nor its tensile response was modified by the flame straightening; nevertheless, a large embrittlement occurred, which is attributed to the precipitation of the tertiary cementite. Another grade, S690QL steel underwent a second tempering, superimposed on the original one, due to the flame heat treatment. The Vickers micro-hardness and the tensile tests showed that a noticeable change in mechanical properties occurred; indeed, the yield stress and tensile strength were clearly below those demanded for this steel. In general, when the critical $\left(A_{3}\right)$ / intercritical $\left(A_{1}\right.$ and $\left.A_{3}\right)$ temperature is reached, the subsequent cooling rate must be controlled to avoid the formation of martensite. In addition, in order to prevent the formation of tertiary cementite in low carbon ferritic-pearlitic

Table 2 Burners and their parameters of spot heating

\begin{tabular}{|c|c|c|c|c|c|c|c|c|c|}
\hline \multirow[t]{2}{*}{ Type of the torches (nozzle size) } & \multicolumn{3}{|c|}{ Pressure (bar) } & \multicolumn{3}{|c|}{ Gas consumption $(1 / h)$} & \multirow{2}{*}{$\begin{array}{l}\text { Torch-workpiece } \\
\text { distance }(\mathrm{mm})\end{array}$} & \multirow{2}{*}{$\begin{array}{l}\text { Diameter of the } \\
\text { flame }(\mathrm{mm})\end{array}$} & \multirow{2}{*}{$\begin{array}{l}\text { Remarks } \\
\text { (on torches) }\end{array}$} \\
\hline & $\mathrm{C}_{2} \mathrm{H}_{2}$ & $\mathrm{C}_{3} \mathrm{H}_{8}$ & $\mathrm{O}_{2}$ & $\mathrm{C}_{2} \mathrm{H}_{2}$ & $\mathrm{C}_{3} \mathrm{H}_{8}$ & $\mathrm{O}_{2}$ & & & \\
\hline $10-30 \mathrm{ACE}$ & 0.7 & - & 3 & 550 & - & 700 & 10 & 5.5 & Cutting nozzle* \\
\hline 10-30 Prop. & - & 0.7 & 3.5 & - & 700 & 2500 & 10 & 4.8 & Cutting nozzle* \\
\hline Nr.6 Weld. tip & 0.8 & - & 3 & 900 & - & 1100 & 9 & 3.0 & Single flame \\
\hline Nr.8 Weld. tip $* *$ & 0.8 & - & 3 & 1200 & - & 1500 & 12 & 3.2 & Single flame \\
\hline LF-H-4 & 0.8 & - & 3 & 1800 & - & 2100 & 15 & 12.0 & Multi flame \\
\hline LF-H-8*** & 1 & - & 4 & 2800 & - & 3000 & 18 & 19.0 & Multi flame \\
\hline PM-5-H & - & 0.8 & 4 & - & 1600 & 5000 & 18 & 25.0 & Multi flame \\
\hline
\end{tabular}

*Only the heating flame was used for the experiments

**Recommended for $10 \mathrm{~mm}$ mild steel

***Recommended for $25 \mathrm{~mm}$ mild steel 
Fig. 1 Burners/torches used for the experiments

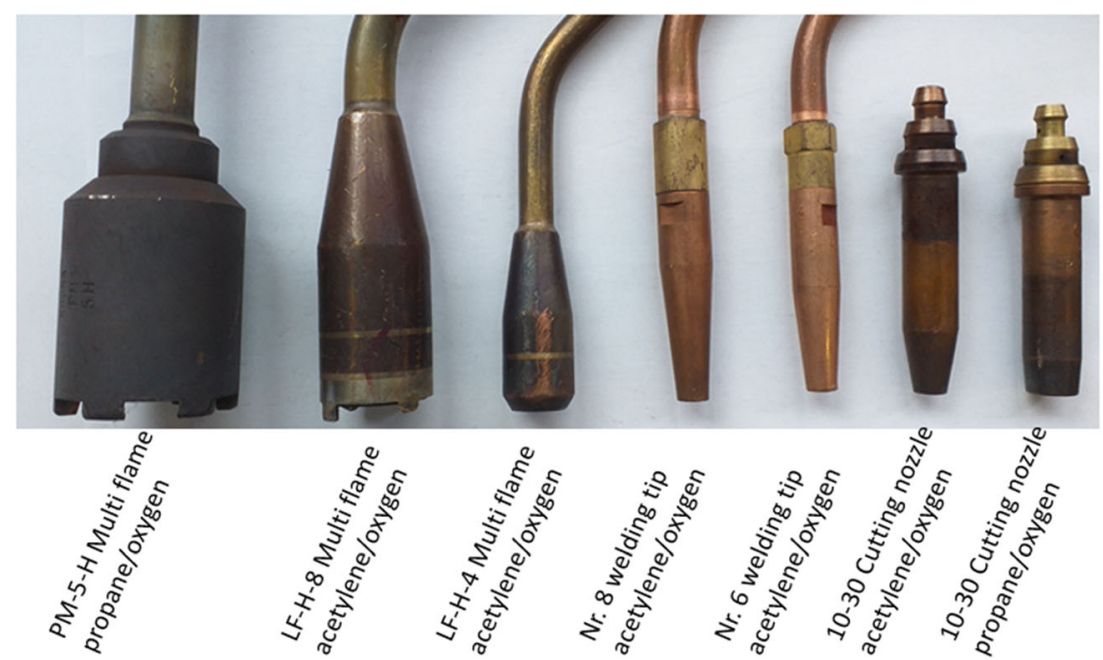

2 Flame straightening technology

steels, low cooling rates below $650^{\circ} \mathrm{C}$ must be avoided [7]. In another study the repeatability of flame straightening was investigated on several steel grades in terms of the mechanical properties. Changes in material properties were small after two cycles of damage and repair. However, additional cycles produced a more brittle material and, in some cases, resulted in fracture of the material [8].

In the present research, the effect of flame straightening on the microstructure and the mechanical properties of three structural steels (S355J2 + N, XAR400, S960QL) is investigated by conventional experiments and physical simulation. The thermal cycles of flame straightening are determined by thermocouple measurement for spot and line heating based on real industrial circumstances. Then the determined thermal cycles of line heating at a given plate thickness are used as input data for the physical simulations. The effect of simulated thermal cycles on microstructure and mechanical properties is investigated by optical microscopic analysis, hardness tests and Charpy V-notch impact tests.
During flame straightening, the size and extent of the heataffected area of the material and its effects are influenced by several factors:

- Heat source performance (the industrial gas used, burner type, size, etc.)

- The size of the heated area, the nature of the heating (spot heating, line heating, large area heating, etc.)

- The maximum temperature reached (its spatial and temporal extent)

- Cooling conditions (material thickness, structure shape, size, air/water cooling, etc.)

\subsection{Industrial gases for flame straightening}

It is generally accepted among welding/cutting experts that the highest temperature flame in practice is an oxygen-acetylene
Fig. 2 Position of thermocouples during spot heating a and line heating $\mathbf{b}$

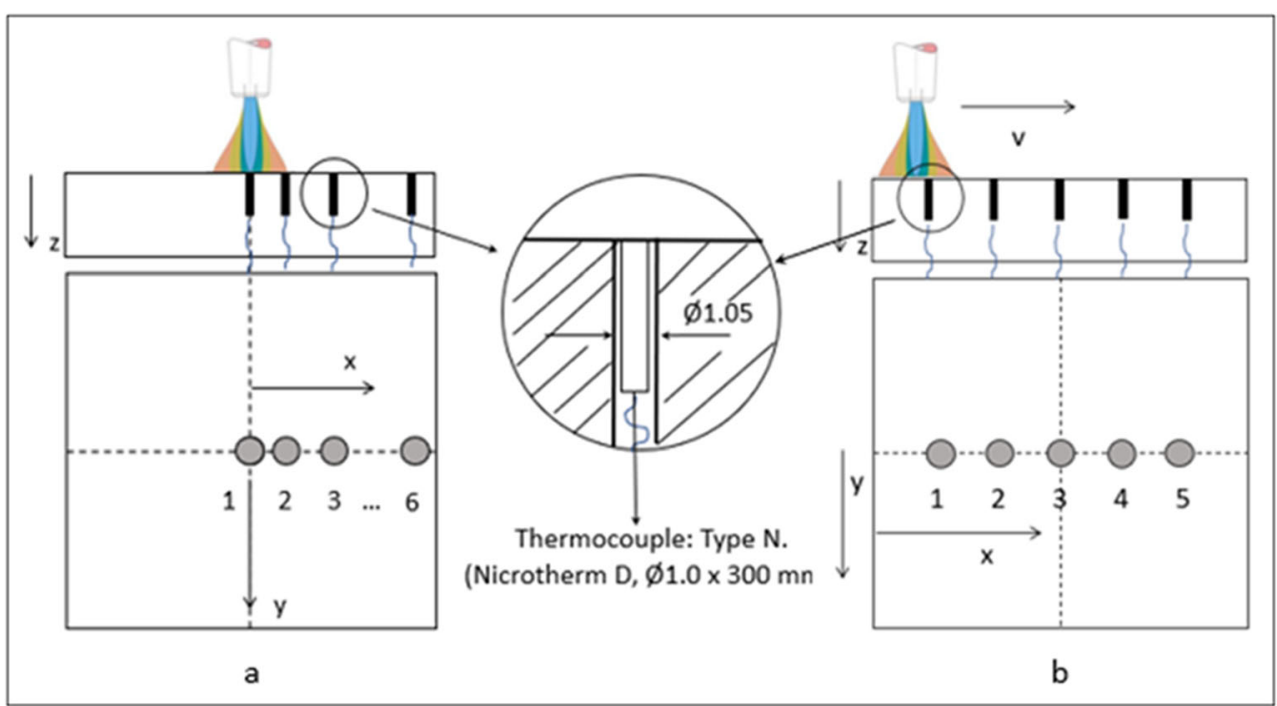


Fig. 3 Recording spot heating thermal cycles on 10 and $25 \mathrm{~mm}$ thick plates with different heat sources (left to right: cutting nozzle, welding tip, multi flame burners)

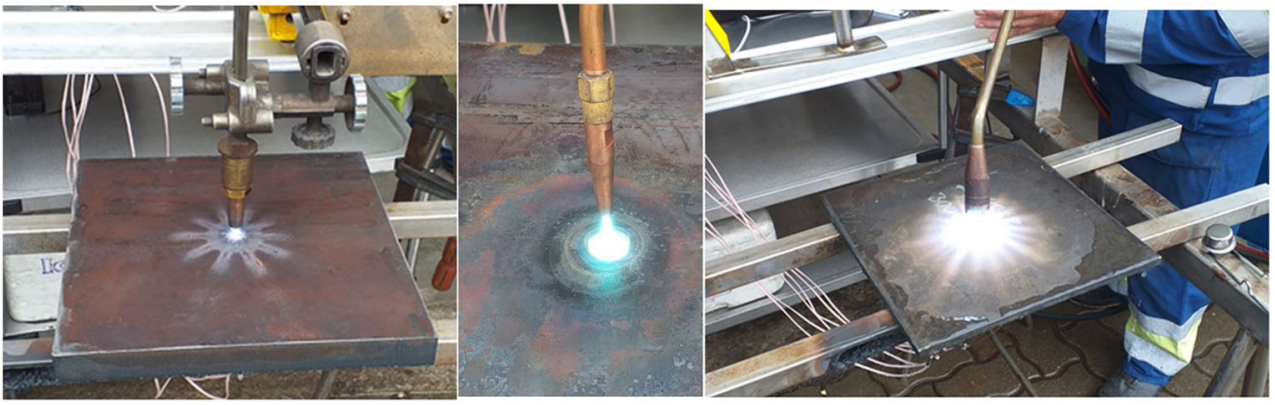

gas flame; therefore this gas mixture typically provides the fastest and most concentrated heating. Due to the high heat flux density (8-12 MW/m $\mathrm{m}^{2}$ [1]) and thus high flame temperature created by the combustion of acetylene with oxygen, the heating is quite intense. The alkane group of hydrocarbons (having the general formula $\mathrm{C}_{\mathrm{n}} \mathrm{H}_{2 \mathrm{n}+2}$ ), which also called as other combustible gases, generally result in a substantially lower heat flux density (4-6 MW/m ${ }^{2}$ in case of propane [1]) during combustion. This type of combustible gas is often referred to as a "slow burning" gas. Another difference is the required oxygen (air) for perfect combustion. Within the combustible gases used in practice, the combustion of acetylene needs the least amount of oxygen (air).

Deciding whether to use a high temperature, intense acetylene-oxygen flame device or a less intense other type of hydrocarbon oxygen or a compressed air burner is not an easy task. It depends on the task at hand which option will achieve a better result with an intense or less intense flame without causing detrimental changes in the material structure. Economic issues can often arise during the consideration, as the cost of purchasing acetylene is significantly higher than the price of other hydrocarbons.

In practice, acetylene-oxygen burners are used in flame straightening, since a fast, well-defined heated area is needed that does not affect the whole cross-section, as already mentioned in the introduction. Due to the nature of the typically manual technology, the risk of local overheating is high for this type of heating. This is much less of a problem when using other hydrocarbons, and there are even tasks where the technological temperature of the straightening must be reached in the full cross-section, in which case a slow burning gas in another alternative.

\subsection{Technological temperature of flame straightening}

As with the limitation of the interlayer temperature used in the welding of multiline welds, strict adherence to the technological temperature of flame processes must be observed. For full cross-section heating, typically not only temperature maximization but also holding time can be important. Prolonged holding at high temperatures allows diffusion processes to take place, which can cause phase separation, change in microstructure and increase in grain size, thus significantly degrading the originally set properties of the steel [9].

The technical report CEN / TR 10347: 2006 "Guidance for forming of structural steels in processing" [10], which provides recommendations for the maximum temperature of each type of steel in case of flame straightening with different techniques, helps to determine the flame equalization temperature (Table 1).
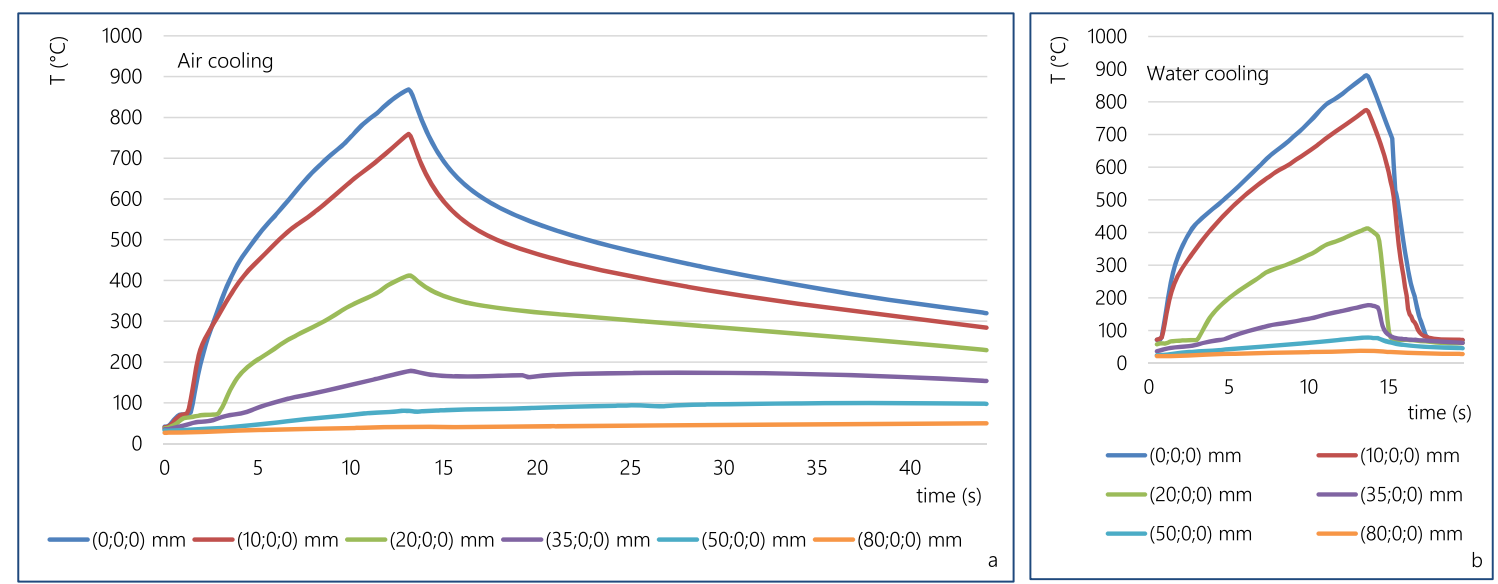

Fig. 4 Thermal cycles at different points on a $10 \mathrm{~mm}$ thick plate when spot heating with No. 8 welding torches for air cooling (a) and water cooling (b) (the location of the measuring points (x;y;z) as shown in Fig. 2a) 
Fig. 5 Heating time (t [heating up]) and cooling times $\left(t_{8 / 5}\right)$ for air and intensive water cooling $\left(\mathrm{T}_{\max }=850^{\circ} \mathrm{C}, \mathrm{t}=10 \mathrm{~mm}\right)$

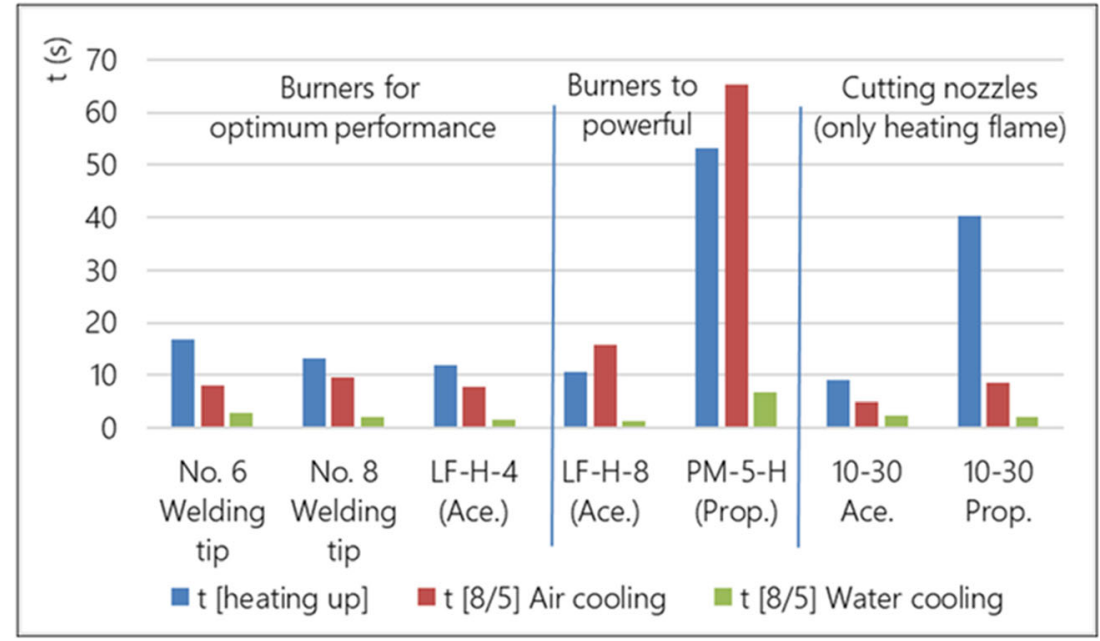

Based on our practical experience, it is not easy to comply with the maximum temperatures given in Table 1, mainly due to the nature of manual technology. Especially during full cross-section heating as well as heating of high-strength steels, it often happens that the temperature of the pieces rises above the recommended value under real heating conditions. Improperly selected high-performance burners can lead to local overheating of structures. In our experiments, the expected effect of such overheating is also examined.

\section{Thermal cycles of flame straightening}

To investigate the thermal cycle and temperature distribution due to flame straightening, experiments were performed on 10, 15, 25 and $30 \mathrm{~mm}$ thick standard S355J2 + $\mathrm{N}$ plates under different boundary conditions. The aim of this section is to characterize the heating and cooling circumstances of flame straightening and to determine the thermal cycles to the later physical simulations on a given material thickness. For our experiments, we chose the most common heating methods for levelling welded structures. We performed both spot heating and line heating by moving the burner mechanically. The examined $300 \times 300 \mathrm{~mm}$ plate was heated at its geometric centre as well as along its centre line. In all cases, acetylene-oxygen and propane-oxygen burners of different capacities (recommended or less recommended for the task) were used (Fig. 1). The types of burners used for the tests and their gas consumption and the gas pressure are summarized in Table 2.

Several thermocouples (typ. N, Nicrotherm D, Ø1.0 $\times$ $300 \mathrm{~mm}$ ) were placed in the workpiece, some of which measured different internal points on the plate and some of which measured changes in the surface temperature of the workpiece (Fig. 2). Thermocouples were fixed in holes made from the underside of the heated piece (friction force held the couples in place). The volume flow of the used gases was measured continuously with rotameter flow metres.
Fig. 6 Temperature change away from the centre of the piece, at the time maximum temperature $\left(\mathrm{T}_{\max }=850^{\circ} \mathrm{C}\right.$ ) is reached (spot heating of the test piece took place with a burner of different operation and performance in the middle, $\mathrm{t}=10 \mathrm{~mm}$ )

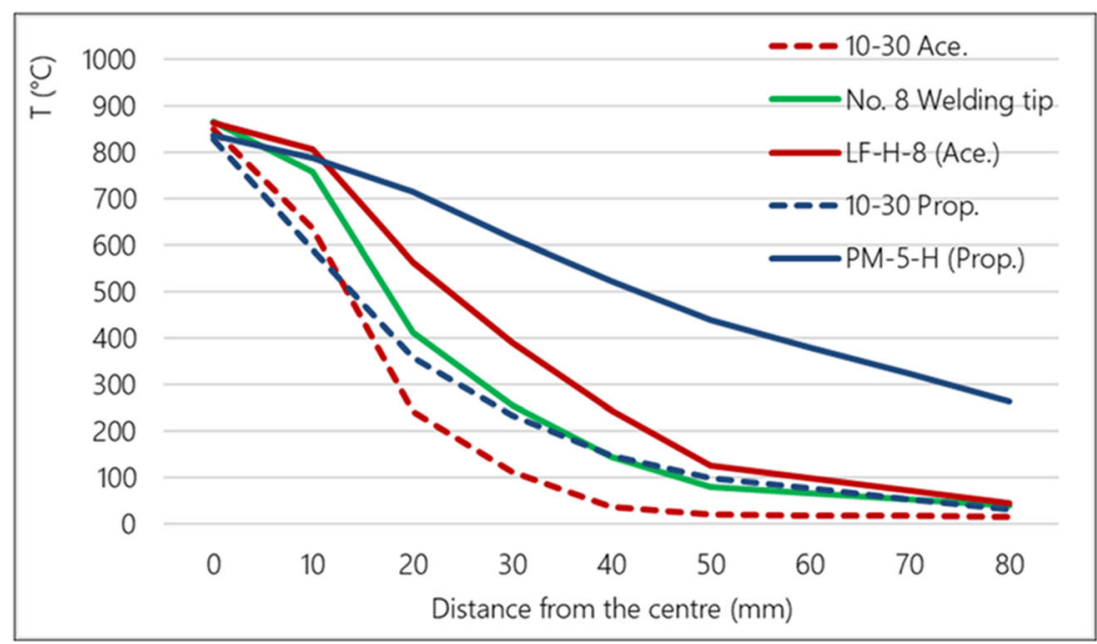


Fig. 7 Examination of heating along the line

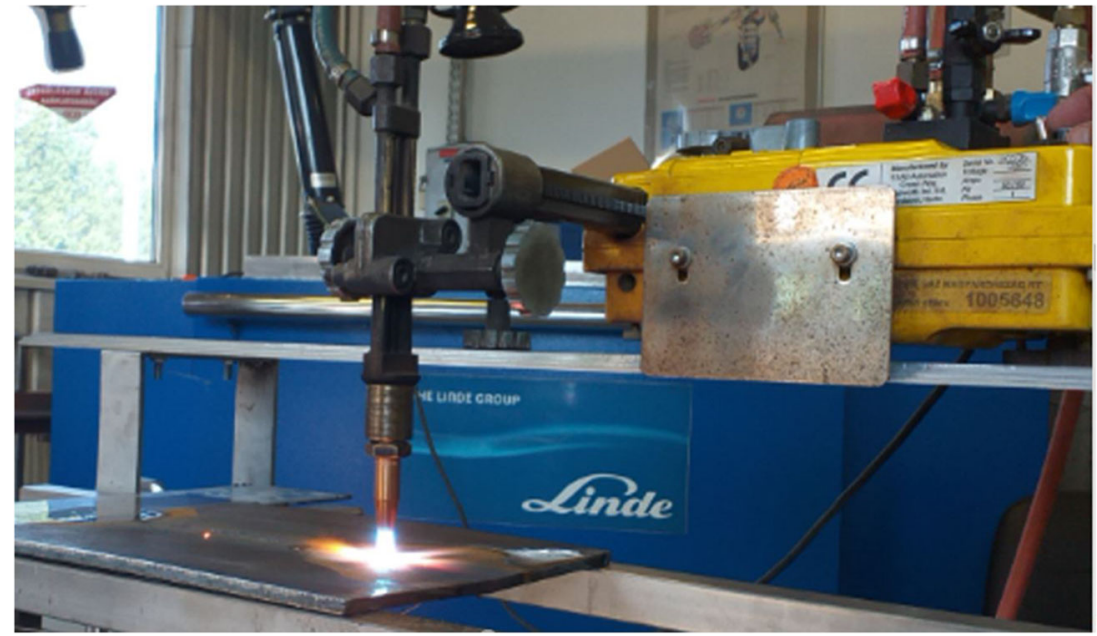

\subsection{Investigation of the effect of heat spot}

The effect of flammable gases and burner performance on single-point heating was investigated. The heat source (burner/ torch) heated the examined plates at one point in the middle of the piece without movement (Fig. 3). The surface temperature of the test pieces was measured directly in the area affected by the flame. For comparability, heating was performed with $850{ }^{\circ} \mathrm{C}$ peak temperature in each case at the flame-affected midpoint. After the heating was stopped, the cooling of the piece was performed by immediate air or intensive water cooling.

Figure 4 shows, by way of example, the thermal cycles of the surface points of a $10 \mathrm{~mm}$ plate for air cooling and intensive water cooling. The heat source is an acetylene/oxygen No. 8 welding tip. The heating time and the cooling characteristics depend on the performance of the heat source for a given steel (Fig. 5). In the case of acetylene-oxygen burners, by increasing the burner performance, the heating time is shortened, but the width of the heat-affected zone increases and the cooling rate slows down. This is especially true for propane/oxygen burners, which result in significantly

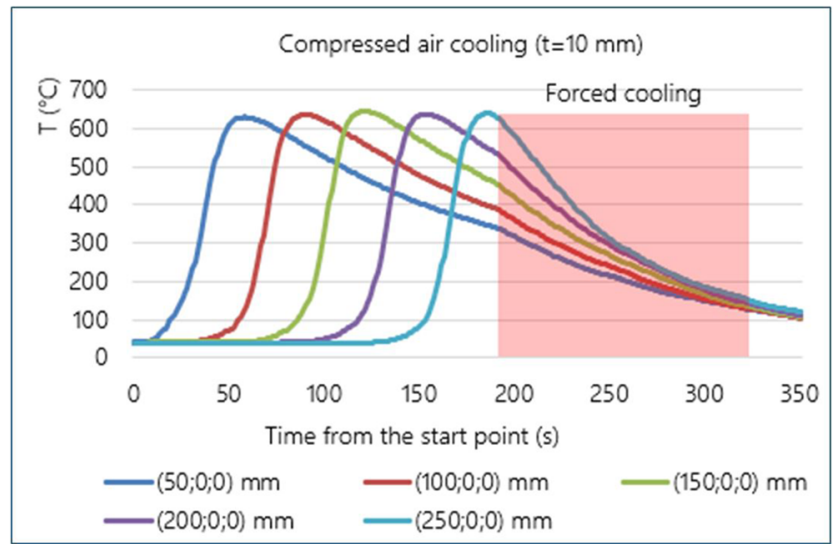

Fig. 8 Thermal cycles at different points on a $10 \mathrm{~mm}$ thick plate when line heating with No. 8 welding torches for compressed air cooling (the location of the measuring points (x;y;z) as shown in Fig. 1b) increased heating times, a wide heated band and slow cooling (Figs. 5 and 6).

Although intensive water cooling is not recommended for professionals during flame straightening under normal conditions, it is sometimes used in practice, so we also examined its effect in our experiments. To characterize the cooling rate, this time we used a cooling time from 800 to $500{ }^{\circ} \mathrm{C}$, like the $\mathrm{t}_{8 / 5}$ cooling time customary in welding technology.

This value has a similar magnitude (typically less than $10 \mathrm{~s}$ ) compared with the cooling times of welding technology under normal conditions. When using a burner with a significantly higher power than recommended, the longer heated area leads to longer cooling times (this is especially true when heating with propane burners, Fig. 5). The value of the cooling time can be critical when using an adequate performance burner followed by an intensive water cooling. The width of the zone heated to high temperature also depends on the power of the burner and the gases required to operate the burner. In the case of propane/oxygen burners with a higher power than recommended, any changes in the material structure occur over a larger area (Fig. 6).

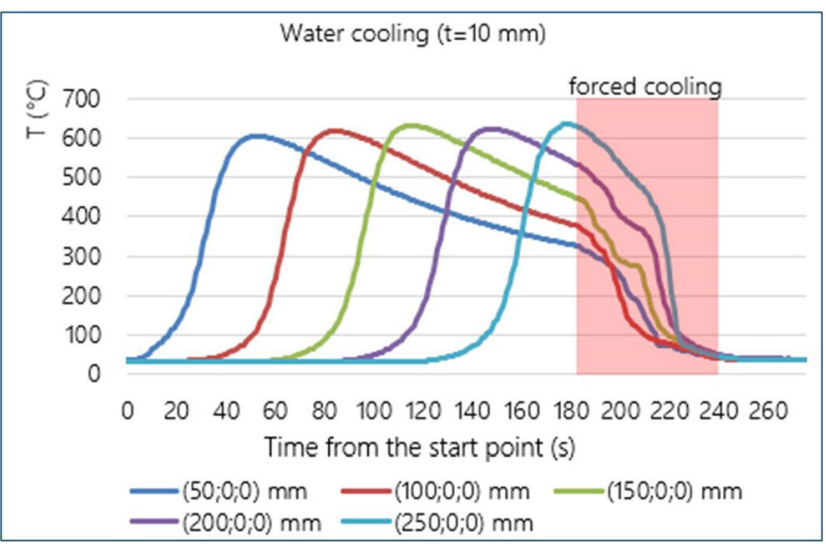

Fig. 9 Thermal cycles at different measurement points on a $10 \mathrm{~mm}$ thick plate when line heating with $\mathrm{Nr} .8$ welding torches for intensive water cooling (the location of the measuring points (x;y;z) as shown in Fig. 1b) 
Fig. 10 Change in cooling time $(\mathrm{t}$ $8 / 5$ ) along the heating line compared to the data for spot heating $(\mathrm{t}=10 \mathrm{~mm}$, heat source No. 8 welding tip)

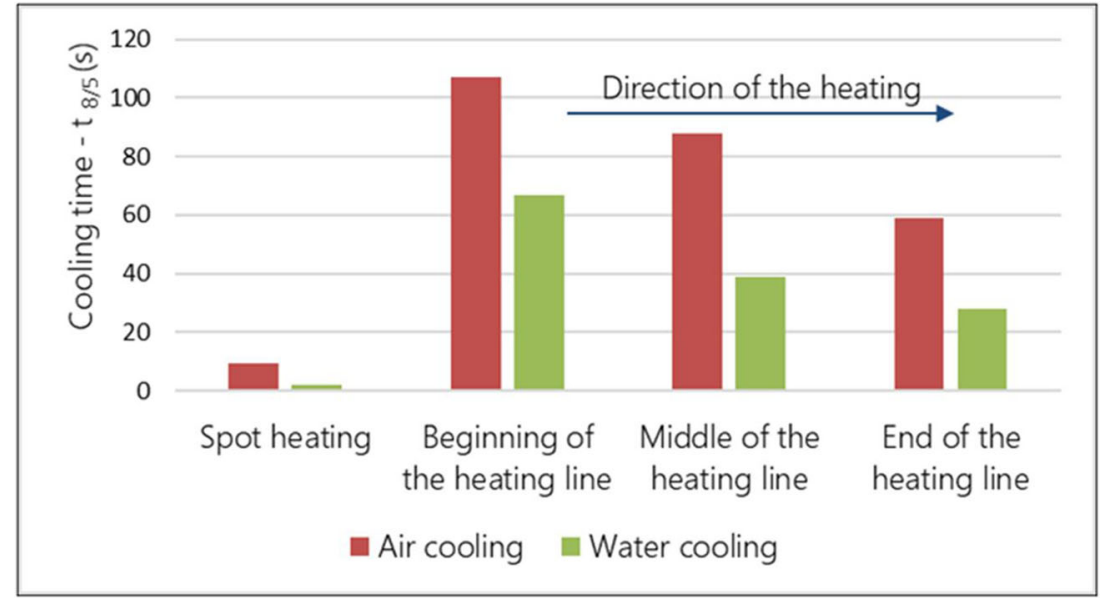

(Note that with the acetylene/pressed air burner indicated in Table 2, the 25-mm plate could not be heated to the target $850{ }^{\circ} \mathrm{C}$, and even with the $10-\mathrm{mm}$ plate the heating time exceeded $1000 \mathrm{~s}$. The technology of straightening temperature with compressed air operated burners is practically unavailable.)

\subsection{Investigation of the temperature distribution in line heating}

During the flame straightening of welded structures, the most common method of heating is to move the torch along a line to be heated (Fig. 7). The speed of the burner, which was mechanically moved along the centre line, was chosen based on preliminary experiments to ensure the formation of the straightening temperature in the upper third of the plate. Depending on the selected speed, the maximum temperature of the plates can be reached differently. (Typical burner movement speeds for $10 \mathrm{~mm}$ plate thickness are $8-11 \mathrm{~cm} / \mathrm{min}$ for movement with the nozzle 8 welding torch and $14-16 \mathrm{~cm} / \mathrm{min}$ for the LF-H-8 burner for $25 \mathrm{~mm}$ plate thickness.) Gas pressure and flow rate were set according to the data in Table 2. We examined various thermal cycles from the less heated to the slight overheating of the workpiece surface along the heating line. Compared with single-spot heating, this time, in addition to air and intensive water cooling, we also examined the cases of compressed (blown) air cooling, which is often used in practice.

As an example, in Figs. 8 and 9, the temperature change (thermal cycle) of some points heated to a maximum temperature of $610-680{ }^{\circ} \mathrm{C}$ are shown (recommended maximum temperature of high strength steels according to Table 1). The figures show the temperature change during the heating of the 300-mm-long plate (Fig. 8 after cooling with compressed air, Fig. 9 with intensive water cooling). The thermoelements were placed every $50 \mathrm{~mm}$ along the heating line. In the case of air cooling, no significant difference was found between the thermal cycles of the points at the beginning and end of the plate. During intensive water cooling, on the other hand, the cooling phase of the formed thermal cycle depends to a large extent on how much area has already been heated. In the case of intensive water cooling that starts immediately after the in-line heating reaches the end of the workpiece, the start of the workpiece (where the heating was started) is already at a much lower temperature than the end, where it was heated by the burner a few seconds earlier, so the end of the workpiece is much more critical for cooling. This means that the characteristics of the cooling depend on where the examination is done along the heated line (note: the thermal cycles were registered from the middle in our experimental work).

Figure 10 shows the change in the cooling times $t_{8 / 5}$ at different sections of the heating line compared to the change experienced with spot heating (see Fig. 5) during the heating of a slightly overheated (maximum temperature approx. $\left.950{ }^{\circ} \mathrm{C}\right) 10-\mathrm{mm}$ plate along the line. Even during water cooling, the value of $t_{8 / 5}$ is generally still above the optimal $5-15 \mathrm{~s}$ (or 6-10 s) range of the S960QL grade $[2,5,6]$.

The cooling characteristics of thermal cycles, recorded with line heating, are significantly higher than the values for spot heating, which is not changed by the more intensive compressed (blow) air cooling. (In practice, the pieces cool below $500{ }^{\circ} \mathrm{C}$ when the blown air is applied.)

\subsection{Simulated thermal cycles}

Physical simulation requires accurate knowledge of heating and cooling conditions of the flame straightening technology. As already mentioned before, the measured thermal cycles are not equal along the heating line (especially in the case of intensive cooling if the heating line is too long). Another problem is that the usual cooling time $t_{8 / 5}$ for arc welding in the case where the heating temperature does not reach $800{ }^{\circ} \mathrm{C}$ (e.g. for high-strength steels this temperature is not 
Fig. 11 Programmed thermal cycles $\left(\mathrm{T}_{\max }=675^{\circ} \mathrm{C}, 800^{\circ} \mathrm{C}\right.$ and $1000^{\circ} \mathrm{C}$ ) for Gleeble simulation based on measurements on a 30-mm thick plate (red: acetylene/oxygen heating; blue: propane/oxygen heating; continuous line: air cooling; dotted line: water cooling)
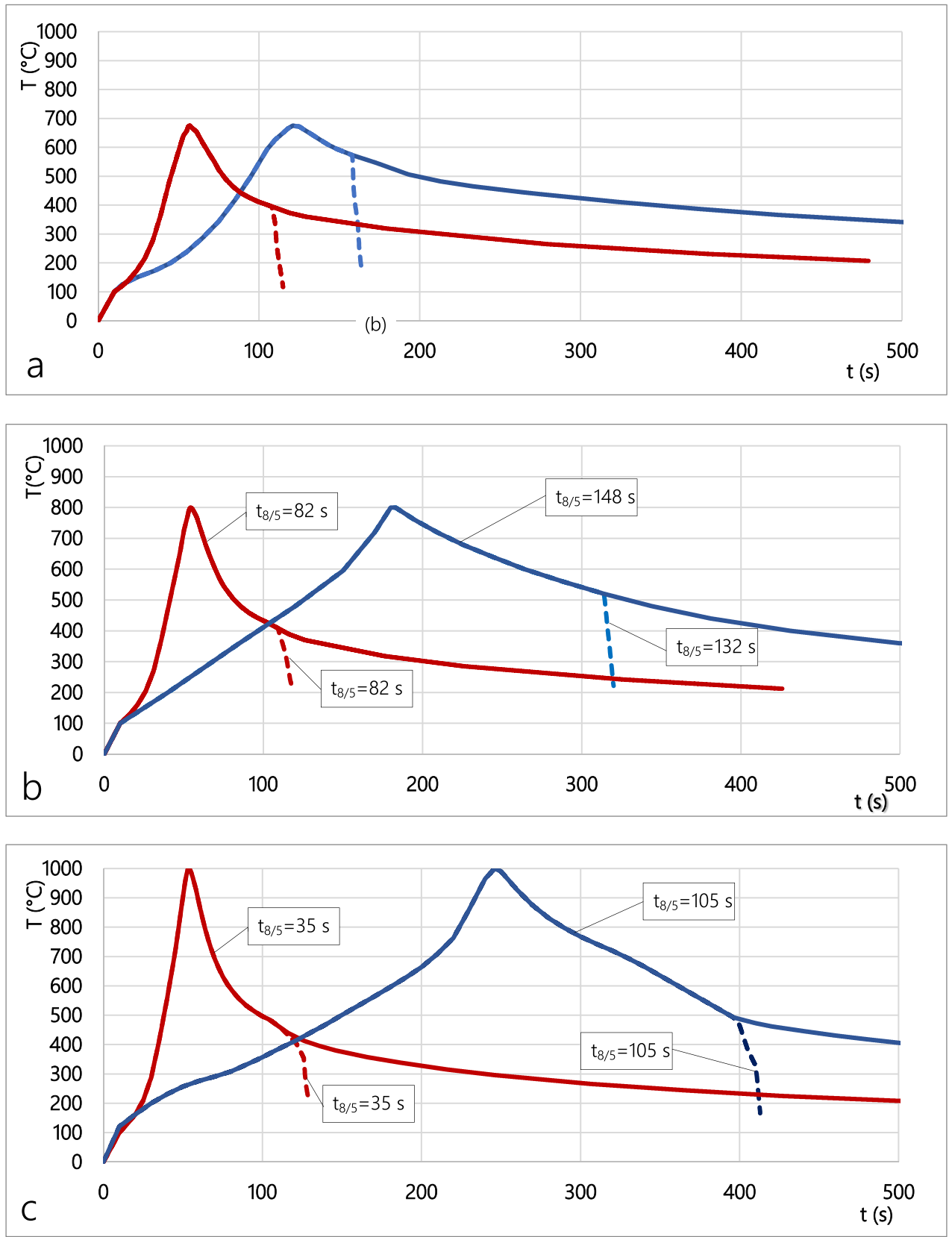

Table 3 Chemical composition in \% of tested steels

\begin{tabular}{lllllllll}
\hline & $\mathbf{C}$ & Si & Mn & P & S & Al & B & Cr \\
S355J2+N & 0.18 & 0.35 & 1.55 & 0.014 & 0.003 & 0.036 & 0.000 & 0.02 \\
XAR400 & 0.15 & 0.19 & 1.32 & 0.011 & 0.002 & 0.094 & 0.002 \\
S960QL & 0.16 & 0.20 & 1.22 & 0.011 & 0.001 & 0.055 & 0.001 & 0.69 \\
& Cu & Mo & Nb & Ni & Ti & V & CE (IIW) & CET \\
S355J2+N & 0.01 & 0.005 & 0.005 & 0.04 & 0.003 & 0.005 & 0.451 & 0.341 \\
XAR400 & 0.03 & 0.020 & 0.023 & 0.06 & 0.006 & 0.000 & 0.518 \\
S960QL & 0.01 & 0.605 & 0.015 & 0.05 & 0.002 & 0.037 & 0.536 \\
\hline
\end{tabular}


Table 4 Characteristic temperatures in ${ }^{\circ} \mathrm{C}$ of phase transformations in the tested steels

\begin{tabular}{lcccc}
\hline Steel & $\mathbf{A}_{\mathbf{c 1}}$ & $\mathbf{A}_{\mathbf{c 3}}$ & $\mathbf{M}_{\mathbf{s}}$ & $\mathbf{M}_{\mathbf{f}}$ \\
\hline S355J2+N & 716 & 818 & 417 & 202 \\
XAR400 & 725 & 839 & 437 & 222 \\
S960QL & 718 & 851 & 425 & 210 \\
\hline
\end{tabular}

recommended) cannot be interpreted. For our simulation experiments, we used the heat cycles in the middle of the heating line as a temperature change with average heating and cooling conditions [11].

Based on the thermal cycles, recorded by line heating presented in the previous section, the $10 \times 10 \times 70 \mathrm{~mm}$ specimens recommended for HAZ (heat-affected zone) tests were loaded with a programmed thermal cycle created for the Gleeble 3500 , while measuring and controlling the specimen temperature with thermocouples welded to it. For the simulation, we used thermal cycles recorded both in air and in water cooling conditions. The points of the workpiece exposed to heat receive different heat loads from the heat source; either laterally or in depth, the maximum temperature that is reached decreases due to the fact that its effect on the steel structure and mechanical properties is not the same (certainly below a certain maximum temperature it is negligible). Thus, our experiments were based on the temperatures $A_{1}$ and $A_{3}$, which are important for metallurgical processes. During the simulations, our test specimens were loaded with thermal cycles below (but close to) the $A_{1}$ temperature of $675{ }^{\circ} \mathrm{C}$ (above the tempering temperature of $\mathrm{Q}+\mathrm{T}$ high strength steel), between $\mathrm{A}_{1}-\mathrm{A}_{3}$ temperature of $800^{\circ} \mathrm{C}$ (average temperature of straightening) and above $\mathrm{A}_{3}$ (overheated) at $1000{ }^{\circ} \mathrm{C}$, in accordance with the actual thermal cycles measured during the thermocouple measurements.

The simulated thermocycles were determined differently based on our measurements. During flame straightening of thicker plates, larger cross-sections needed to be heated due to the appropriate effectivity of straightening. Therefore, by considering the large number of physical simulations, only thermal cycles measured of the $30-\mathrm{mm}$ plate were used for Gleeble studies (acetylene-oxygen heating, propane-oxygen heating, with air and water cooling) (Fig. 11) [12]. It should be also remarked that significant differences in the characteristics of the thermal cycles in the function of plate thickness were not observed since the performance of the burners increased proportionately with the plate thickness.

Although the thermal cycles were determined for the $\mathrm{S} 355 \mathrm{~J} 2+\mathrm{N}$ steel, they can be also used for the characterization of the investigated other grades due to the similar heat conductivity. XAR400 and S960QL can be also considered as low-alloyed steels; therefore there is no significant difference in the thermophysical properties that determines their heating and cooling behaviour during flame straightening.

\subsection{The tested steels}

In addition to the mild steel, which can now be considered a classic in the $355 \mathrm{MPa}$ strength category, experiments were performed on a frequently used wear-resistant steel and a high-strength structural steel.

High-wear XAR400 steel is mainly used for high-wear parts of agricultural vehicles and earthmoving machinery

Table 5 The effect of heating on the $\mathrm{S} 355 \mathrm{~J} 2+\mathrm{N}$ steel $(\mathrm{t}=15 \mathrm{~mm})$

\begin{tabular}{|c|c|c|c|c|}
\hline $\begin{array}{l}\text { Burning gas and } \\
\text { burner }\end{array}$ & \multicolumn{2}{|c|}{$\begin{array}{c}\text { Acetylene/oxygen } \\
\text { (burner: No.8 welding nozzle) }\end{array}$} & \multicolumn{2}{|c|}{$\begin{array}{c}\text { Propane/oxygen } \\
\text { (burner: 10-30 cutting nozzle) }\end{array}$} \\
\hline Cooling type & Air cooling & Water cooling & Air cooling & Water cooling \\
\hline $\begin{array}{l}\text { Macroscopic } \\
\text { images }\end{array}$ & $10 \mathrm{~mm}$ & & $\stackrel{10 \mathrm{~mm}}{\stackrel{\longrightarrow}{\rightleftarrows}}$ & $\stackrel{10 \mathrm{~mm}}{\stackrel{⺊}{\rightleftarrows}}$ \\
\hline \multicolumn{5}{|c|}{ Microscopic images ( $0.5 \mathrm{~mm}$ below the surface)/Hardness } \\
\hline Base material & \multicolumn{4}{|c|}{ Heated material } \\
\hline 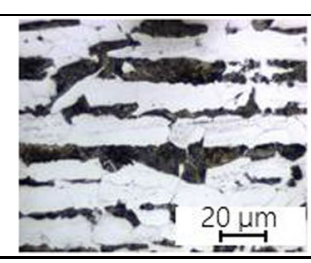 & 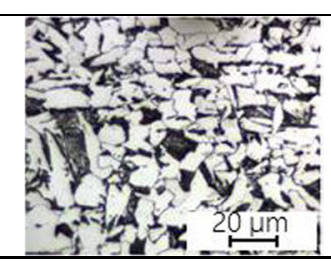 & 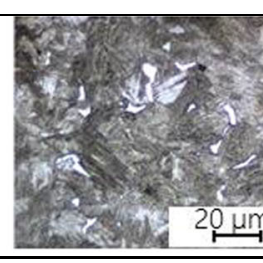 & 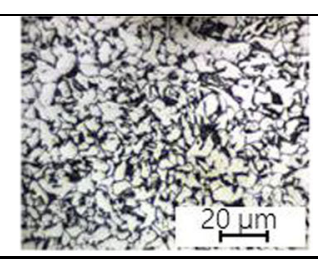 & 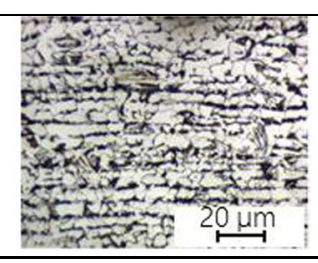 \\
\hline 152 HV10 & $182 \mathrm{HV} 10$ & 405 HV10 & $182 \mathrm{HV} 10$ & $188 \mathrm{HV} 10$ \\
\hline
\end{tabular}


Table 6 The effect of heating on the XAR400 steel $(\boldsymbol{t}=25 \mathrm{~mm})$

\begin{tabular}{|c|c|c|c|c|}
\hline $\begin{array}{l}\text { Burning gas and } \\
\text { burner }\end{array}$ & \multicolumn{2}{|c|}{$\begin{array}{l}\text { Acetylene/oxygen } \\
\text { (burner: LF-H-8) }\end{array}$} & \multicolumn{2}{|c|}{$\begin{array}{l}\text { Propane/oxygen } \\
\text { (burner: PM-5-H) }\end{array}$} \\
\hline Cooling type & Air cooling & Water cooling & Air cooling & Water cooling \\
\hline Macroscopic images & & & & \\
\hline \multicolumn{5}{|c|}{ Microscopic images ( $0.5 \mathrm{~mm}$ below the surface)/Hardness } \\
\hline Base material & \multicolumn{4}{|c|}{ Heated material } \\
\hline 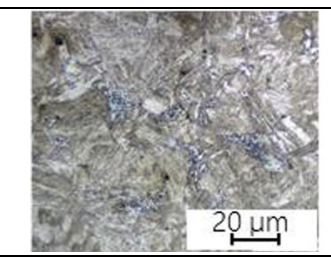 & 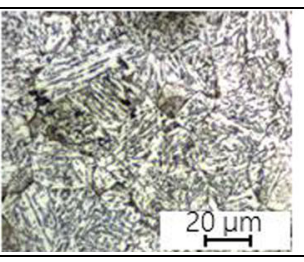 & 1) & 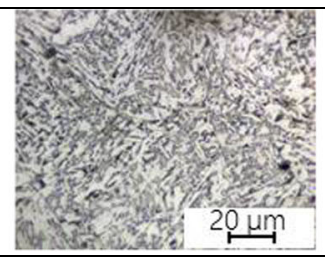 & 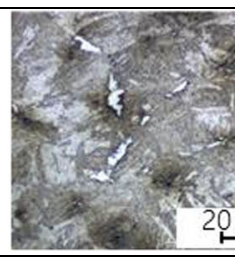 \\
\hline 394 HV10 & 259 HV10 & 362 HV10 & 243 HV10 & 366 HV10 \\
\hline
\end{tabular}

("yellow goods"), typically in the form of welded structures [13]. One of the most common applications of S960QL high-strength steel is the extendable steel structure of mobile crane booms, but it is also often used in the construction of high-performance towed vehicle and trailer chassis structures, which are also made by various welding processes [14].
In both cases, the desired high strength and abrasion resistance are produced by the base material manufacturers with special production technology. The welding of base materials often requires geometric correction with flame, which locally causes a degree of material structure that can cause a change in mechanical properties that can be critical to the integrity of the entire structure [8]. The chemical composition of the tested

Table 7 The effect of heating on the S960QL steel $(t=10 \mathrm{~mm})$

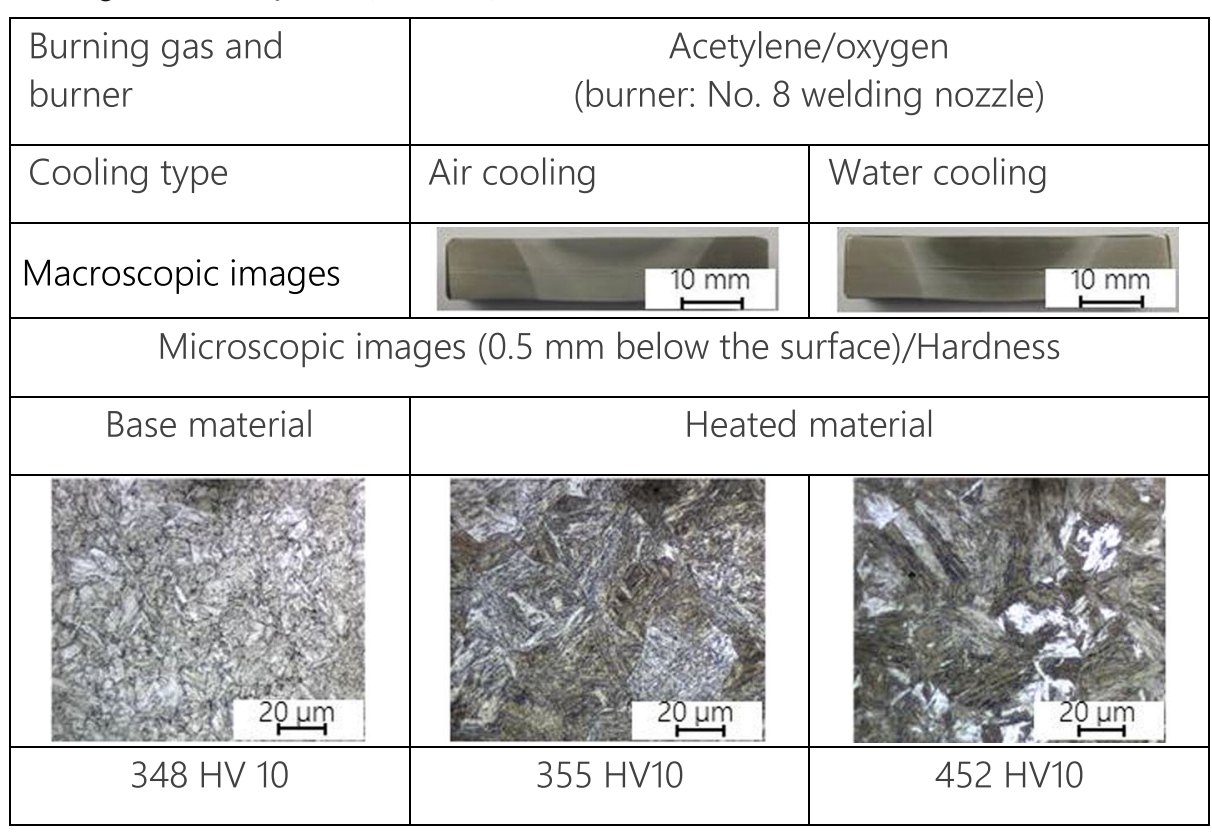


Table 8 The Gleeble physical simulation results on the S355J2 + N steel

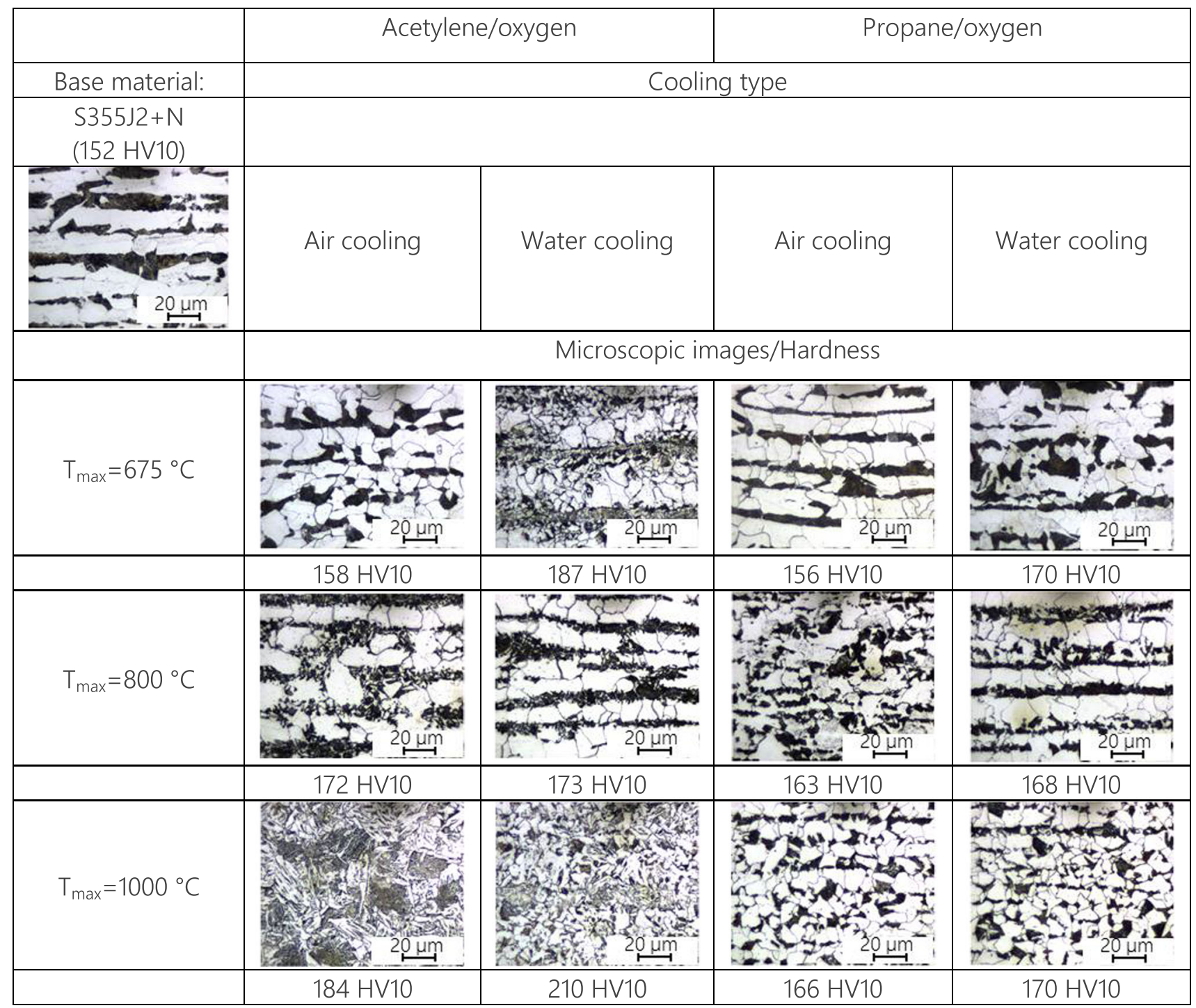

$15 \mathrm{~mm}$ plate mild steel, $25 \mathrm{~mm}$ plate wear-resistant steel and $10 \mathrm{~mm}$ S960QL steel is shown in Table 3.

Based on the chemical composition, the characteristic temperatures of phase transformation were estimated according to [15], as it is summarized in Table 4. Based on Fig. 11 during acetylene heating the water cooling started nearly from the $M_{s}$ temperature of the given steel, while in propane heating the water cooling started from a higher temperature than $M_{s}$.

\section{Results of flame straightening experiments}

The investigated plates were heated along the line, which is the most common method during welding, using the appropriate tools and parameters to the given plate thickness. Thermocouples were not used in these experiments, since the heating and cooling circumstances have been characterized in the previous section. Some differences in the thermal cycles might be possible due to the uneasy controllability of the process, although all experiments tried to be performed according to the same methodology and parameters. Optical microscopy (around $0.5 \mathrm{~mm}$ below the surface) and macrohardness tests were performed at the geometric centre of the $300 \times 300 \mathrm{~mm}$ heated plates (right in the middle of the area affected by the flame, where the maximum temperature was measured by thermocouples is typically around $1000^{\circ} \mathrm{C}$ ). It is important to note that during heating with propane, the peak temperature was generally lower, around $800{ }^{\circ} \mathrm{C}$. The microstructural analysis was carried out using a Zeiss Axio Observer D1m inverted microscope. The polished samples were etched by $2 \%$ Nital in all cases. A Reicherter UH 250 universal macro-hardness tester was used for the hardness 
Table 9 Simulation results on the XAR400 steel

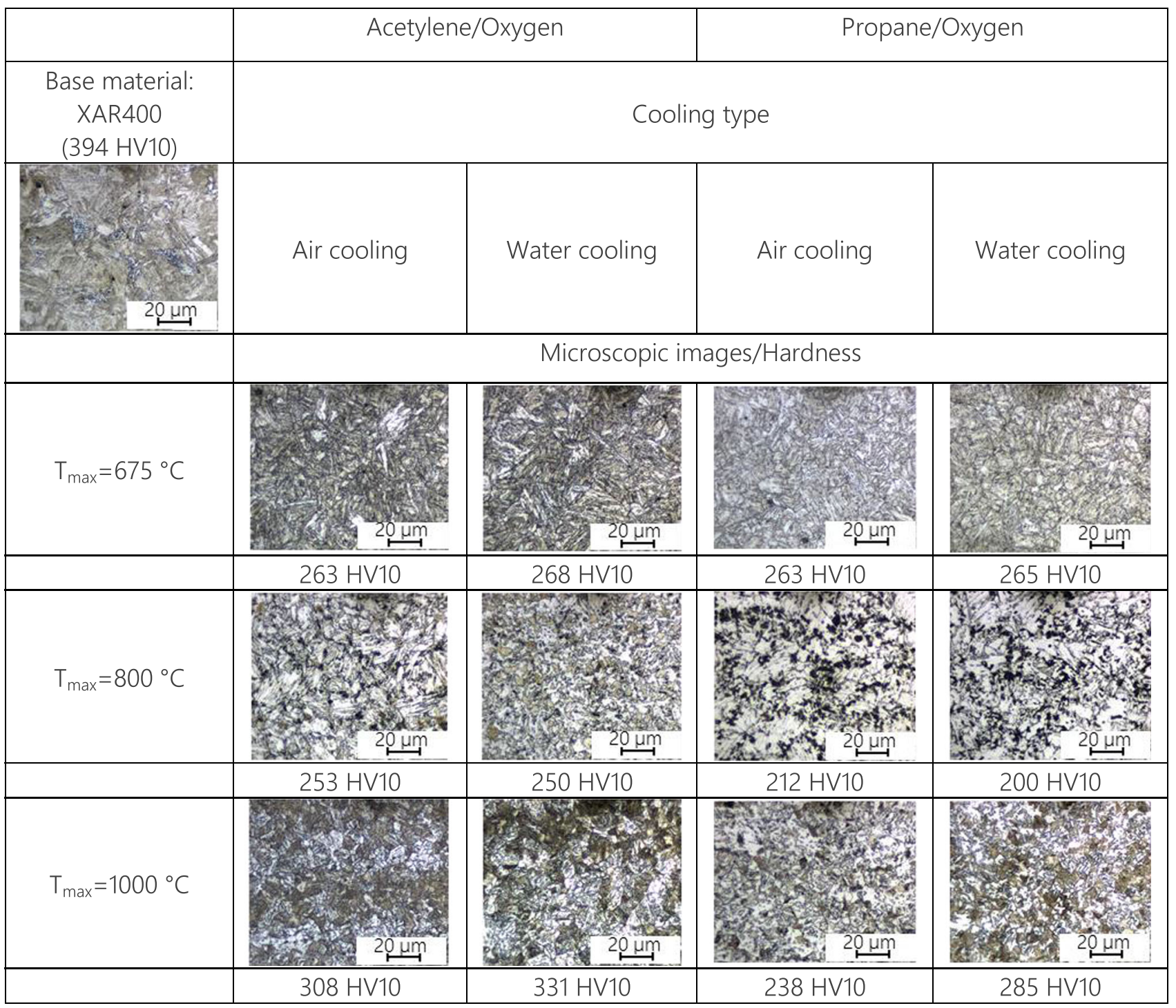

measurements. Hardness tests were performed at the geometric centre of the HAZ, vertically to the surface. Ten indentations were made with $0.5 \mathrm{~mm}$ equal distance between each. The average of the first two indentations $(0.5$ and $1 \mathrm{~mm}$ below the surface), characterizing the microstructural images in Tables 5, 6, 7, was determined. The results obtained during the microscopy examinations were compared with the properties and characteristics of the base materials. (Material S960QL was not heated with a propane burner.)

For all three steels, it can be observed that the microstructure and mechanical properties created during the production of the base material typically changed in an unfavourable direction under the influence of heat. On the microscopic images, the white parts indicate the presence of ferrite. Cooling of the wear-resistant steel in air resulted in a bainite-like microstructure, while water cooling yielded a bainite-martensitic microstructure mixed with a low amount of ferrite. S960QL steel is basically bainite-martensitic, and in the case of rapid cooling it is practically completely martensitic. In steel $\mathrm{S} 355 \mathrm{~J} 2+\mathrm{N}$, the rolled direction microstructure was transformed and recrystallized. The significantly increased hardness due to water cooling associated with acetylene heating indicates brittleness of this part of the material. In the other cases, there has been only a slight increase in hardness. In the optical microscopy images, grain refinement was visually observed, although not quantified, in all cases compared with the base material.

In the case of XAR400 steel, significant softening occurred mainly due to the heat effect of slow air cooling; however, the hardness was still under the base material value during the faster water cooling. The local abrasion resistance of the area affected by the flame is likely to decrease significantly 
Table 10 Simulation results on the S960QL steel

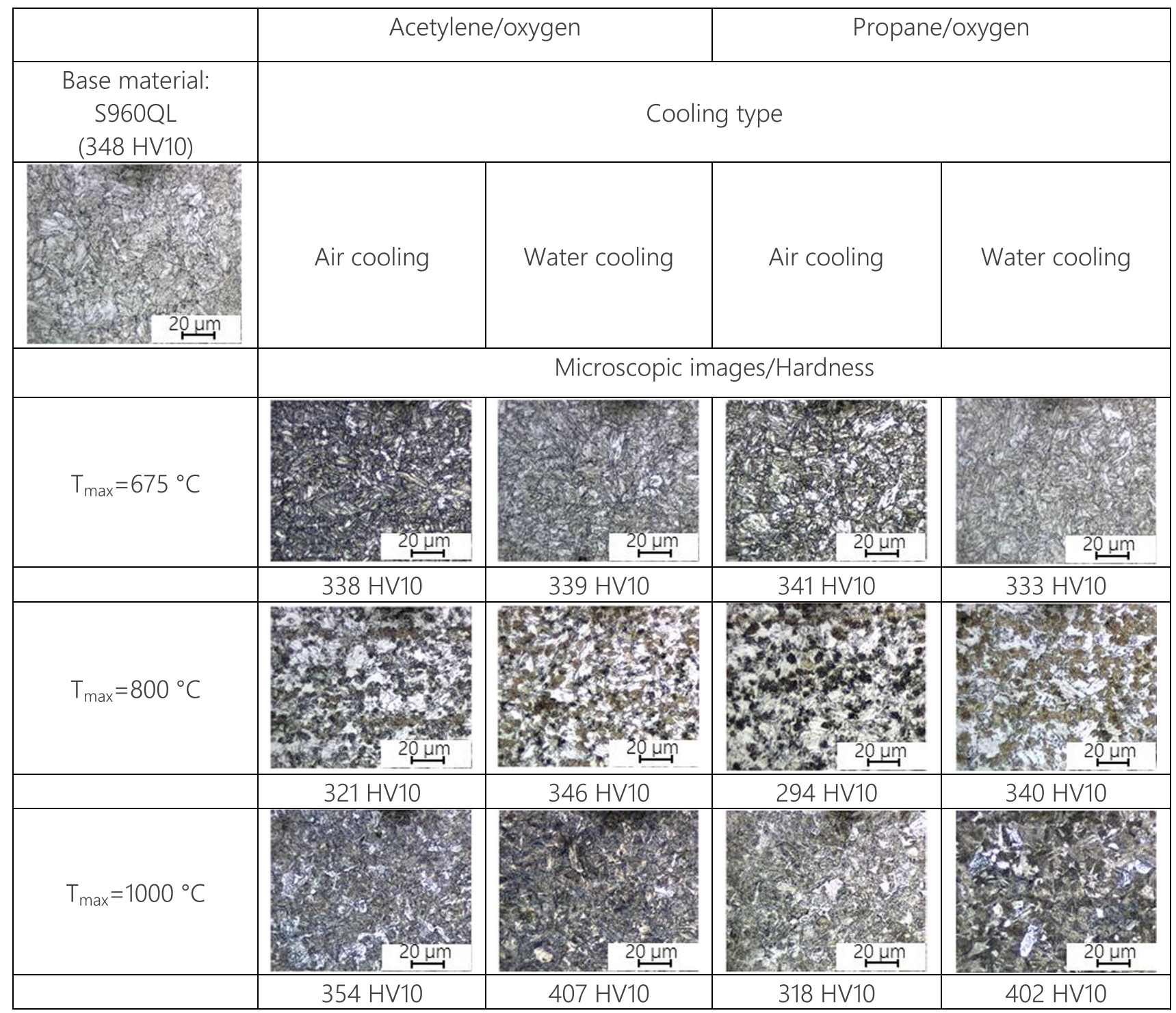

compared with the base material. There is practically no significant difference in the effect of acetylene and propane heating on the material structure in the studied area. (However, based on the examination of thermal cycles, it can be assumed that the size of the area affected by heat is larger with propane heating, which is also confirmed by macroscopic investigations in Table 6 showing the size of the heated zone.)

For steel S960QL, hardness is not as important as in wearresistant steels, although the increase in hardness associated with intensive water cooling is expected to be accompanied by a decrease in toughness. During water cooling, the degree of hardening reached the maximum permissible value of 450 HV10 for steel group 3 according to the relevant CR ISO 15608 standard (the examined steel belongs to this group)
$[16,17]$. Grain coarsening is observed, which can result in local changes in the toughness of the material. The differences between XAR400 and S960QL can be attributed to the different phase transformation behaviour and microstructure evolution of these two steels during cooling.

\section{Results of the Gleeble physical simulation tests}

After the physical simulation of flame straightening according to the thermal cycles presented in Fig. 11, optical microscopy analysis and hardness measurements (5 indentations in a $10 \times$ $10 \mathrm{~mm}$ cross-section of the test pieces, evenly distributed) were performed on the heated part of the Gleeble specimens 
Fig. 12 Hardness values of the base material, flame-heated test plates and Gleeble simulation results $(\mathrm{S} 355 \mathrm{~J} 2+\mathrm{N}, \mathrm{t}=15 \mathrm{~mm})$

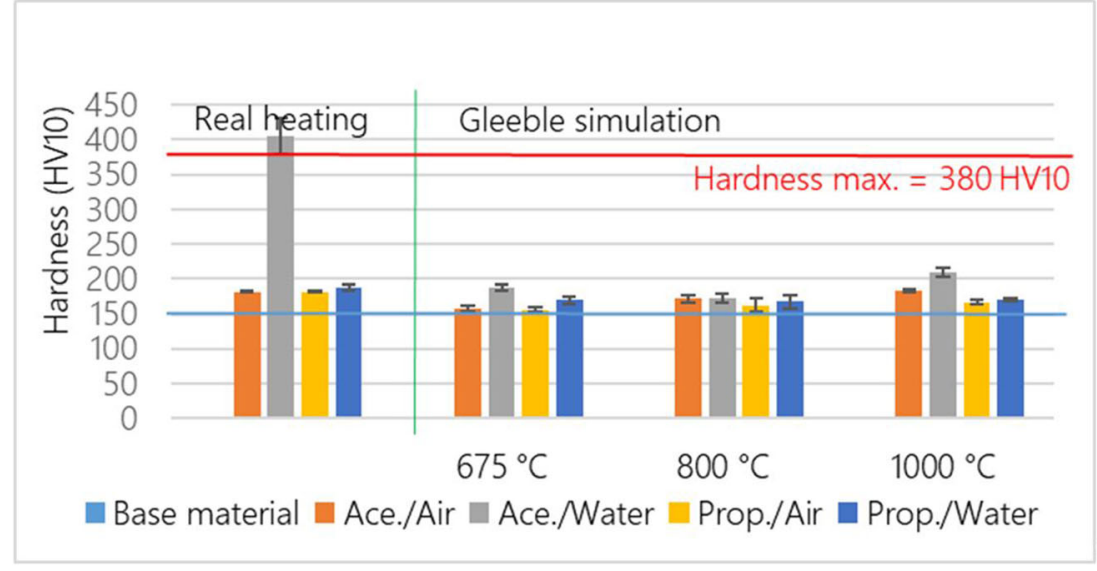

(the centre of the test piece). Microscopic images of the simulation results for the three steel base materials are shown in Tables 8, 9 and 10. For hardness value comparisons, the measured results are shown in Figs. 12, 13 and 14 where the average hardness of the first two indentations below the surface of the real workpieces is given for the comparison with the simulations. The registered absorbed energy values during the Charpy V-notch tests are presented in Figs 15, 16 and 17.

In general, the real heating conditions and the slightly different test results obtained in the Gleeble simulations (which can be seen in both the hardness and the microscopic images) are probably due to the geometric difference between the real and simulation specimens, the differences in the thermal cycles at the different plate thicknesses and the occasionally different maximum temperatures under real and simulation conditions (the tested area may not have heated to $1000{ }^{\circ} \mathrm{C}$ ).

\subsection{Evaluation of the experimental results of S355J2 + N steel}

For heating below $\mathrm{A}_{1}$ temperature, the hardness values were virtually unchanged from the initial hardness of the base material, regardless of the nature of the heating and cooling in accordance with [7] when S235JR was investigated.
However, compared with the microstructure of the base material, the ferrite-perlite transformation begins, although the initial rolled elongated structure is still clearly visible. Although, significant changes were not observed in the microstructure, embrittlement might occur due to the possible presence of tertiary cementite during slow cooling (as in S235JR at [7]).

In the case of the heat effect at the temperature between $A_{1}$ and $A_{3}$, especially in the case of prolonged air cooling, the transformation of the structure (decomposition of perlite) can already be perceived, which, however, is only partial due to the incomplete austenitization process. While in the case of rapid cooling, the stretched structure can still be clearly removed, the transformation creates a new structure in the case of longer processes. The small increase in hardness compared with the base material is negligible.

At temperatures above $A_{3}$, the original structure was transformed to form a completely new structure during the simulation of flame straightening with acetylene. The austenitic transformation has taken place and bainite occurred in the microstructure, while the rapid cooling resulted in the formation of some martensite islands at the location of prior perlite grains, which is also confirmed by the increase in hardness values. During heating with propane, the microstructure
Fig. 13 Hardness values of the base material, flame-heated test plates and Gleeble simulation results (XAR400, $\mathrm{t}=25 \mathrm{~mm}$ )

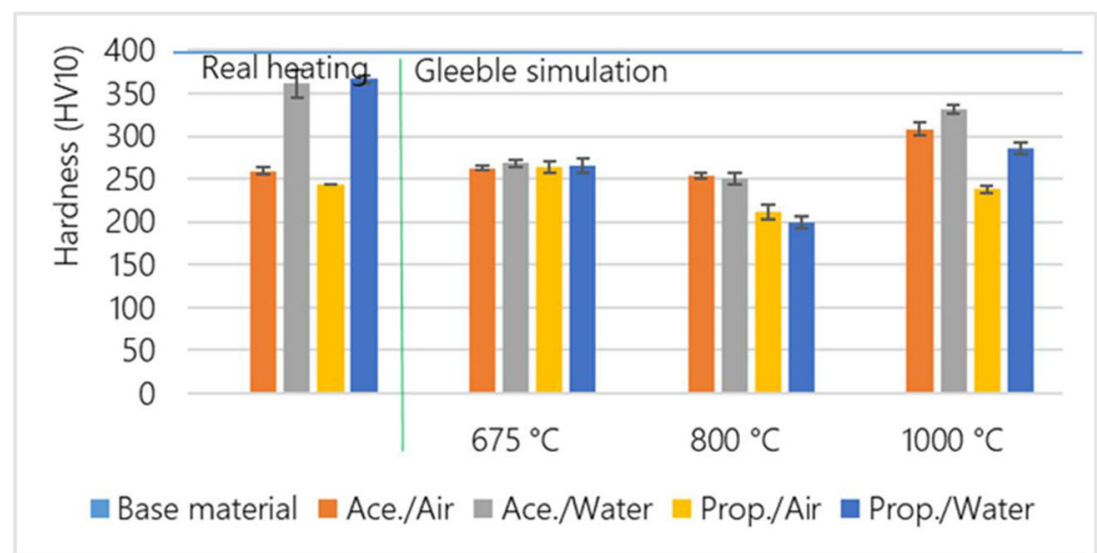


Fig. 14 Hardness values of the base material, flame-heated test plates and Gleeble simulation results $(\mathrm{S} 960 \mathrm{QL}, \mathrm{t}=10 \mathrm{~mm})$

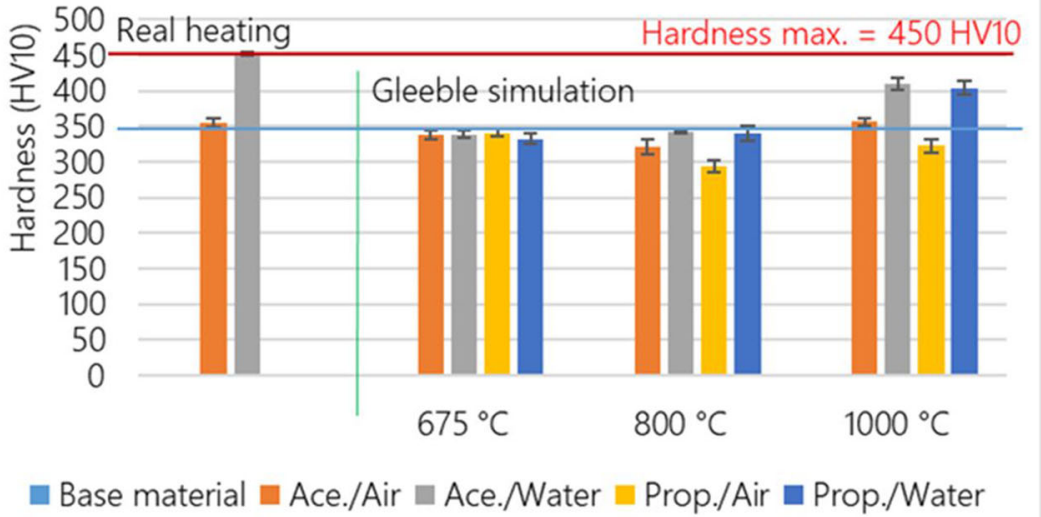

remained similar (ferrite-perlite) since the slow cooling resulted in a microstructure closer to the equilibrium state.

\subsection{Evaluation of the experimental results of wear resistant XAR400 steel}

In the area heated to the maximum temperature of $675^{\circ} \mathrm{C}$, the steel essentially underwent high-temperature tempering and the hardness of $400 \mathrm{HV} 10$ set during the production of the base material dropped to 260-270 HV10 (regardless of the intensity of cooling). Although the area reaching $\mathrm{T}_{\max }=$ $800{ }^{\circ} \mathrm{C}$ is already partially in the austenitic range, due to the relatively short times and low temperature, there is no time to form a homogeneous austenite. The amount of perlite in the transformed parts is higher during longer thermal cycles (with propane heating), while mostly martensite-austenite islands can be observed during the acetylene cycles, especially with water cooling.

The significantly overheated areas, reaching $1000{ }^{\circ} \mathrm{C}$, already have a longer austenitization stage, although the cooling is not intense enough, but a microstructure with higher hardness is obtained compared with the lower peak temperatures. However, the hardness of the original base material is not achieved. Even the cooling rate of acetylene heated samples with water is not enough to obtain the martensite-based hard microstructure. Overall, when this material is flame straightened, the abrasive wear resistance of the area affected by the flame is basically lost.

\subsection{Evaluation of the experimental results of S960QL type steel}

For this high strength steel, both real flame straightening and Gleeble simulation experiments clearly demonstrated the negative effect of water cooling even with overheating. In the overheated relatively thin material, rapid cooling causes significant hardening after the start of the austenitization process. This increase in hardness may indicate a decrease in toughness for high strength steels, which can cause crack initiation in the area exposed to heat. This can be particularly critical for vehicles where significant dynamic effects can occur. At 675 and $800{ }^{\circ} \mathrm{C}$ peak temperatures hardening is not observed; however a slight softening occurs during acetylene/oxygen heating, which does not endanger the static tensile load bearing behaviour of the material. However, the application of propane with air cooling may cause significant softening during overheating $\left(800\right.$ and $\left.1000^{\circ} \mathrm{C}\right)$.
Fig. 15 The measured impact energy values during the Charpy $\mathrm{V}$-notch impact tests on the Gleeble simulated heat-affected areas of flame straightening $(\mathrm{S} 355 \mathrm{~J} 2+\mathrm{N})$

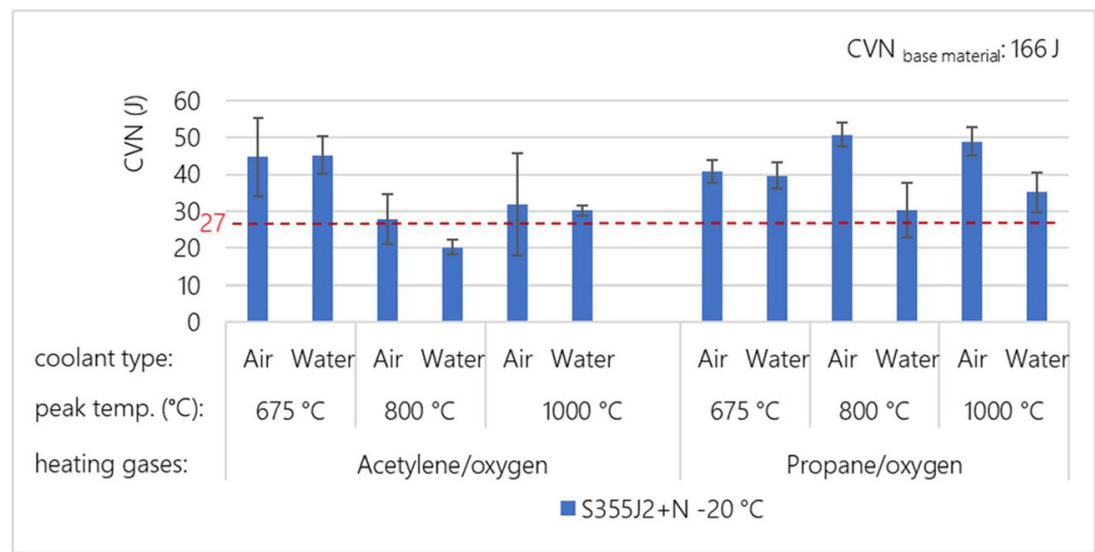


Fig. 16 The measured impact energy values during the Charpy $\mathrm{V}$-notch impact tests on the Gleeble simulated heat-affected areas of flame straightening (XAR400)

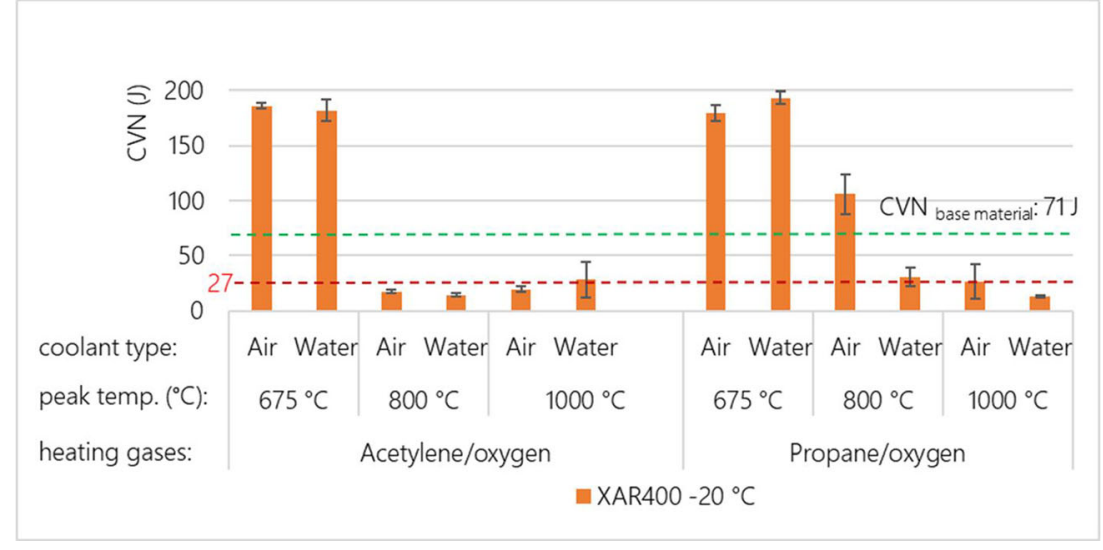

\subsection{Charpy V-notch impact tests}

Charpy V-notch impact tests (according to EN ISO 9016) were done by PSD 300 impact testing equipment on the Gleeble simulated heat-affected areas of flame straightening. The standardized $10 \times 10 \times 55 \mathrm{~mm}$ specimens were prepared from the samples. Figures 15, 16 and 17 illustrate the registered impact energy values (CVN) on the investigated three materials during air and water cooling for acetylene/oxygen heating and propane/oxygen heating. The results are evaluated in terms of the required minimum $\mathrm{CVN}$ values $(27 \mathrm{~J}$ for $\mathrm{S} 355 \mathrm{~J} 2+\mathrm{N}$ at $-20^{\circ} \mathrm{C}$ and $\mathrm{S} 960 \mathrm{QL}$ at $-40{ }^{\circ} \mathrm{C}$ ) by the governing base material standards. No standardized requirement is given for the investigated XAR400 steel. Therefore, in all cases the measured impact energy values of the base materials are also illustrated in the figure. The test temperature was $-20{ }^{\circ} \mathrm{C}$ at $\mathrm{S} 355 \mathrm{~J} 2+\mathrm{N}$ and XAR400 and $-40{ }^{\circ} \mathrm{C}$ at S960QL in accordance with the base material certificate and the standard.

In general, similar tendencies can be observed during the comparison of acetylene/oxygen and propane/oxygen heating as a function of the temperature. Among the investigated three peak temperatures, $675^{\circ} \mathrm{C}$ was beneficial regarding the toughness properties for the S960QL and the XAR400 steels due to the tempering of martensitic microstructure, relatively independently from the heating and cooling circumstances, while in the case of the $\mathrm{S} 355 \mathrm{~J} 2+\mathrm{N}$ steel, the impact energy values were much lower compared with the base material, although the $27 \mathrm{~J}$ requirement was fulfilled. Heating at $800{ }^{\circ} \mathrm{C}$ peak temperature resulted in detrimental effects on the toughness of all steels, especially in faster heating and cooling conditions (acetylene/oxygen + water), which can be connected to the presence of local brittle zones, characteristic to this intercritical temperature range. The impact energy values drastically dropped for the XAR400 and S960QL steels; however, for $\mathrm{S} 355 \mathrm{~J} 2+\mathrm{N}$ these values were also under the requirement. With propane/oxygen heating and air cooling, the impact energy values were above the requirement for $\mathrm{S} 355 \mathrm{~J} 2+$ $\mathrm{N}$ and XAR400, but the toughness of S960QL remained low due to the relatively high carbon equivalent. During the Gleeble simulation of overheating $\left(\mathrm{T}_{\max }=1000^{\circ} \mathrm{C}\right)$, the shorter thermal cycles resulted in higher toughness values in the S960QL steel due to the fine-grained microstructure. In the case of S355J2 + N and XAR400, low-impact energy values were registered, similarly to at $800{ }^{\circ} \mathrm{C}$.

\section{Conclusions}

A detailed mapping of the heating and cooling circumstances of flame straightening with acetylene and propane through a
Fig. 17 The measured impact energy values during the Charpy $\mathrm{V}$-notch impact tests on the Gleeble simulated heat-affected areas of flame straightening (S960QL)

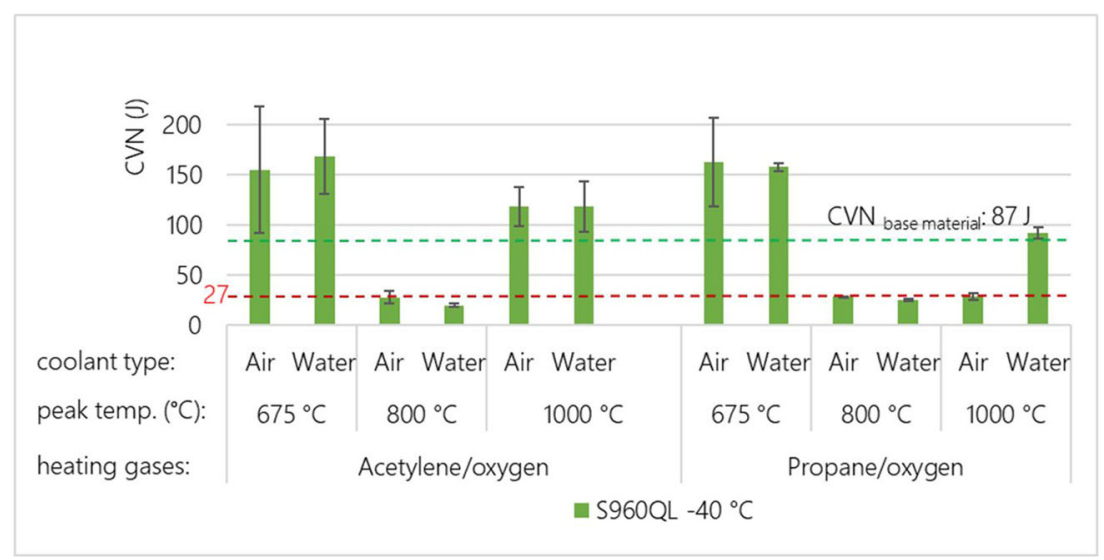


series of thermocouple experiments were carried out. Then physical simulations and materials tests (optical microscopy analysis, hardness measurements, Charpy V-notch impact testes) were performed to predict the expected effect of flame straightening in the case of the three steel grades (S355J2+ N, XAR400, S960QL). The results of physical simulations and real flame straightened samples were compared and discussed, although the strength and toughness values determined with physical simulation could not be directly transferred to real flame straightened components. With the latter, a gradient of microstructure and properties exists due to the thermal gradient; therefore, mechanical properties of real components are always integral values because of different contribution of different local microstructures. Based on the performed experimental programme the following conclusions can be drawn:

- In the examination of the thermal cycles of flame straightening the cooling time concept $\left(\mathrm{t}_{8 / 5}\right)$ used to characterize, the arc welding heat processes cannot be fully applied to flame technology. In the case of modern structural steels, especially for large area heating, in many cases, the maximum temperature may not even reach $800{ }^{\circ} \mathrm{C}$, and the heating and cooling times are significantly longer than we are accustomed to during welding.

- The experiments have shown that flame straightening can have a significant effect on the original properties of the base material.

- Even during the flame straightening of S355J2 + N, a significant toughness reduction can be expected above $\mathrm{A}_{1}$ temperature, especially with acetylene/oxygen heating. Occasionally significant hardening can be observed in the acetylene-/oxygen-heated samples after water cooling.

- In the case of XAR400 wear-resistant steels, even a correctly implemented technology can lead to a reduction in local wear resistance due to the significant softening compared with the base material. Furthermore, the toughness significantly drops in the case of intercritical heating.

- In the investigated S960QL high strength steel, significant softening was not observed; however, the toughness can drastically drop above the $A_{1}$ temperature.

- Comparing the influence of the different flammable gases, generally acetylene resulted in more favourable hardness distribution in XAR400 and S960QL.

- The inter- and supercritical temperature should be avoided in all steels; however, the subcritical temperature can be beneficial to the toughness properties of the S960QL and XAR400 in the case of both heating and cooling conditions.

- Based on the overall evaluation of the results, the maximum peak temperature during flame straightening should be under the $A_{1}$ temperature for all investigated steels in order to achieve an acceptable toughness and hardness level. However, it should be considered that even in the subcritical range, XAR400 can soften to a significant degree.

- Therefore, the CEN/TR 10347:2006 technical report entitled "Guidance for forming of structural steels in processing" should be revised in terms of the performed experiments, and $900{ }^{\circ} \mathrm{C}$ short-term heating should be also avoided for $\mathrm{S} 355 \mathrm{~J} 2+\mathrm{N}$ steel, because of the significant toughness reduction, similarly to the S960QL steel.

Acknowledgements This research was supported by the European Union and the Hungarian State, co-financed by the European Regional Development Fund in the framework of the GINOP-2.3.4-15-201600004 project, aimed to promote the cooperation between the higher education and the industry. The authors are grateful for the Linde Gas Hungary Ltd. for ensuring the base materials and experimental background for the real flame straightening experiments.

Funding Open Access funding provided by University of Miskolc.

Open Access This article is licensed under a Creative Commons Attribution 4.0 International License, which permits use, sharing, adaptation, distribution and reproduction in any medium or format, as long as you give appropriate credit to the original author(s) and the source, provide a link to the Creative Commons licence, and indicate if changes were made. The images or other third party material in this article are included in the article's Creative Commons licence, unless indicated otherwise in a credit line to the material. If material is not included in the article's Creative Commons licence and your intended use is not permitted by statutory regulation or exceeds the permitted use, you will need to obtain permission directly from the copyright holder. To view a copy of this licence, visit http://creativecommons.org/licenses/by/4.0/.

\section{References}

1. (2009) Linde Group: Fundamentals of Flame Straightening, White Paper, pp. 4-26.

2. Mičian M, Harmaniak D, Nový F, Winczek J, Moravec J, Trško L (2020) Effect of the $t_{8 / 5}$ cooling time on the properties of S960MC steel in the HAZ of welded joints evaluated by Thermal Physical Simulation. Metals 10:229

3. Tervo H, Mourujärvi J, Kaijalainen A, Kömi J (2018) Mechanical properties in the physically simulated heat-affected zones of $500 \mathrm{MPa}$ offshore steel for arctic conditions. In: Jármai K, Bolló B (eds) Vehicle and Automotive Engineering 2. VAE 2018. Lecture Notes in Mechanical Engineering. Springer, Cham

4. Maurer W, Ernst W, Rauch R, Vallant R, Enzinger N (2015) Evaluation of the factors influencing the strength of HSLA steel weld joint with softened HAZ. Weld World 59:809-822. https:// doi.org/10.1007/s40194-015-0262-z

5. Gáspár M (2019) Effect of Welding Heat Input on Simulated HAZ Areas in S960QL High Strength Steel. Metals 9:1226

6. Lukács J, Dobosy Á (2019) Matching effect on fatigue crack growth behaviour of high-strength steels GMA welded joints. Weld World 63:1315-1327. https://doi.org/10.1007/s40194-01900768-3

7. Lacalle R, Álvarez JA, Ferreño D et al (2013) Influence of the flame straightening process on microstructural, mechanical and fracture 
properties of S235 JR, S460 ML and S690 QL structural steels. Exp Mech 53:893-909. https://doi.org/10.1007/s11340-013-9723-8

8. Avent R, Mukai JD, Robinson PF (2000) Effect of heat straightening on material properties of steel. J Mater Civ Eng 12(3):188-195. https://doi.org/10.1061/(ASCE)0899-1561(2000)12:3(188)

9. Schäfer D, Rinaldi V, Beg D, Može P, Lacalle R, Portilla J, Ferreño D, Álvarez J A, Willms R, Schütz J (2012) Optimization and improvement of the flame straightening process (Optistraight). Final report, Research Fund for Coal and Steel, European Commission. https://doi.org/10.2777/37733

10. CEN/TR 10347 (2006) Guidance for forming of structural steels in processing. pp. 9-10.

11. Nacsa G, Gyura L (2019) Effect of flame straightening on material properties of Q + T high strength steels, MultiScience - XXXIII. microCAD International Multidisciplinary Scientific Conference, Miskolc-Egyetemváros, Magyarország: Miskolci Egyetem, pp. 112. Paper: B-6, 12. https://doi.org/10.26649/musci.2019.014

12. Gyura L, Gáspár M, Balogh A (2021) Investigation of thermal effects of flame straightening on high-strength steels. In: Jármai K, Voith K (eds) Vehicle and Automotive Engineering 3. VAE
2020, Springer, Singapore, Lecture Notes in Mechanical Engineering 171:526-538. https://doi.org/10.1007/978-981-159529-5 46

13. ThyssenKrupp Europe (2015) XAR wear-resistant steels, https:// www.mtladv.com/wp-content/uploads/2016/01/xarr_2015_en. pdffg, (last accessed 18/05/2020)

14. SSAB Homepage, https://www.ssab.hu/products/brands/strenx/ products/strenx-960, (last accessed 18/05/2020)

15. Andrews KW (1965) Empirical formulae for the calculation of some transformation temperatures. J Iron Steel Inst 203:721-727

16. CR ISO 15608 (2000) 2000 Welding. Guidelines for a metallic material grouping system

17. EN ISO 15614-1 (2017) 2017 Specification and qualification of welding procedures for metallic materials. Welding procedure test. Part 1: Arc and gas welding of steels and arc welding of nickel and nickel alloys

Publisher's note Springer Nature remains neutral with regard to jurisdictional claims in published maps and institutional affiliations. 